\title{
Development of ECU Capable Grey-Box Models from Detailed Models-Application to a SCR Reactor
}

\author{
Santhosh R. Gundlapally ${ }^{1} \cdot$ Iakovos Papadimitriou $^{1} \cdot$ Syed Wahiduzzaman ${ }^{1} \cdot{\text { Tian } \text { Gu}^{2}}^{2}$
}

Received: 26 January 2016 /Revised: 21 March 2016/Accepted: 12 April 2016 / Published online: 10 June 2016

(C) Springer International Publishing Switzerland 2016

\begin{abstract}
Selective catalytic reduction (SCR) of NOx with $\mathrm{NH}_{3}$ is a widely used after-treatment technology for reducing the NOx emissions from diesel engines. Mathematical models play an important role in analyzing and optimizing SCR reactors and also in controller design. Detailed mathematical models of SCR reactors consist of a number of coupled differential and algebraic equations, which can only be solved numerically. Due to the limited computational capability of engine control unit (ECU) and hardware-in-loop (HIL) systems, it is not practical to solve detailed model equations on these systems in real time, and hence, there is a need for reduced-order models. In this work, we provide a systematic procedure for deriving reduced-order models from detailed models of a SCR reactor. This systematic procedure consists of making reasonable assumptions, good input signal design, and system identification procedure. The reduced-order model consists of non-stiff system of equations which can be solved with an explicit solver, is two to three orders of magnitude faster than the detailed model, and has same level of accuracy as detailed model. The proposed model remains fundamentalbased, with model parameters directly related to physical and chemical properties of the catalyst, and can be used on ECU and HIL systems to predict ammonia storage, NOx conversion efficiency, and ammonia slip during transient operating conditions. Moreover, it is shown that the model equations can be easily linearized around various operating points, thus
\end{abstract}

Santhosh R. Gundlapally

s.gundlapally@gtisoft.com

1 Gamma Technologies, 601 Oakmont Lane, Suite 220, Westmont, IL 60559, USA

2 Department of Chemical and Biomolecular Engineering, University of Houston, 4800 Calhoun Rd, Houston, TX 77004, USA allowing the development of advanced control strategies based on linear control theory. Although mainly demonstrated in the context of SCR reactors, the procedures can be applied to other monolith reactors as well.

Keywords SCR · Grey box · Model-based control - System identification $\cdot$ State estimation $\cdot$ Linear control theory

\begin{tabular}{|c|c|}
\hline \multicolumn{2}{|c|}{ Abbreviations } \\
\hline$A_{\mathrm{f}, i}\left(A_{\mathrm{b}, i}\right)$ & $\begin{array}{l}\text { Pre-exponential factor for forward (reverse) } \\
\text { reaction } i\end{array}$ \\
\hline$C_{0}$ & Total molar concentration, $\mathrm{mol} / \mathrm{m}^{3}$ \\
\hline$C_{i}^{\text {in }}$ & Inlet concentration of species $i, \mathrm{~mol} / \mathrm{m}^{3}$ \\
\hline$C_{i}^{\text {out }}$ & Outlet concentration of species $i, \mathrm{~mol} / \mathrm{m}^{3}$ \\
\hline$C_{\mathrm{pf}}\left(C_{\mathrm{pw}}\right)$ & Heat capacity of fluid phase (wall), $\mathrm{J} /(\mathrm{kg} \mathrm{K})$ \\
\hline$C_{\mathrm{s}}$ & Site density, $\mathrm{mol} / \mathrm{m}^{3}$ washcoat \\
\hline$D_{\mathrm{f}}$ & Diffusivity of a species in fluid phase, $\mathrm{m}^{2} / \mathrm{s}$ \\
\hline$D_{\mathrm{s}}$ & $\begin{array}{l}\text { Effective diffusivity of a species in washcoat, } \\
\mathrm{m}^{2} / \mathrm{s}\end{array}$ \\
\hline$h$ & Heat transfer coefficient, $\mathrm{W} /\left(\mathrm{m}^{2} \mathrm{~K}\right)$ \\
\hline$\Delta H$ & Heat of reaction vector, $\mathrm{J} /(\mathrm{mol} \mathrm{K})$ \\
\hline$k_{\mathrm{f}}$ & Thermal conductivity in fluid phase, $\mathrm{W} /(\mathrm{m} \mathrm{K})$ \\
\hline$k_{\mathrm{w}}$ & Thermal conductivity of wall, $\mathrm{W} /(\mathrm{m} \mathrm{K})$ \\
\hline$k_{\mathrm{f}, i}\left(k_{\mathrm{b}, i}\right)$ & Forward (reverse) rate constant of reaction $i$ \\
\hline$k_{\mathrm{m}}$ & External mass transfer coefficient vector, $\mathrm{m} / \mathrm{s}$ \\
\hline$L$ & Length of the channel, $\mathrm{m}$ \\
\hline$N u$ & Nusselt number \\
\hline$r$ & Reaction rate vector \\
\hline$R_{\Omega}$ & One fourth the channel hydraulic diameter, $\mathrm{m}$ \\
\hline$S h$ & Sherwood number \\
\hline$t$ & Time, s \\
\hline$T_{\mathrm{f}}\left(T_{\mathrm{s}}\right)$ & Temperature of fluid (solid) phase, $\mathrm{K}$ \\
\hline$T_{f}^{\mathrm{in}}$ & Temperature at channel inlet, $\mathrm{K}$ \\
\hline
\end{tabular}


$u \quad$ Average velocity, $\mathrm{m} / \mathrm{s}$

$v^{T} \quad$ Stoichiometric coefficients vector

$\boldsymbol{X}_{\mathrm{fm}} \quad$ Species mole fraction vector in bulk/fluid phase

$\boldsymbol{X}_{\mathrm{wc}} \quad$ Species mole fraction vector in washcoat

$\boldsymbol{X}_{\mathrm{fm}}^{\mathrm{in}} \quad$ Species mole fraction vector at channel inlet

$y \quad$ Length co-ordinate along washcoat direction

$x \quad$ Length co-ordinate along axial direction

$\rho_{\mathrm{f}} \quad$ Density of fluid mixture, $\mathrm{kg} / \mathrm{m}^{3}$

$\rho_{\mathrm{w}} \quad$ Density of wall, $\mathrm{kg} / \mathrm{m}^{3}$

$\varepsilon \quad$ Porosity of washcoat

$\theta \quad$ Fractional coverage of vacant sites

$\delta_{\mathrm{c}} \quad$ Washcoat thickness, $\mathrm{m}$

$\delta_{\mathrm{w}} \quad$ Effective wall thickness, $\mathrm{m}$

\section{Introduction}

Selective catalytic reduction (SCR) of $\mathrm{NOx}$ with $\mathrm{NH}_{3}$ is being used to meet the increasingly stringent government standards of NOx emissions from diesel engines and it is the most active research area in all of exhaust emission control. Since the technology's first commercial applications in the last decade, the deNOx efficiency of SCR reactors has increased about ten times with improvement in catalyst compositions, system design and control [1]. As efficiencies increase, the operations of SCR systems are becoming the bottleneck for further performance improvement. Thus, SCR system control (including urea dosing, ammonia slip control, etc.) is attracting more and more attention. Model-based control is an emerging approach for achieving better SCR control. Skaf et al. [2] and Yuan et al. [3] recently reviewed current status on the development of SCR control. Reactor modeling usually consists of two layers of mathematical models-reactor models, which capture mass and heat transport in the reactors, and reaction (or kinetic) models, which describe the reaction mechanisms. In case of SCR reactors, many modeling studies can be found in the literature [4-7] regarding system analysis, design, and control. With different level of complexity in the reactor and kinetic models, these works can be generally categorized into three groups. The first group of models is mostly developed by chemists and chemical engineers. From their knowledge in chemical reactors and chemistry, they propose physics-based partial differential equation (PDE) models describing the convection-diffusion-reaction system incorporating detailed kinetic models to capture all physical and chemical behaviors of the reactor as accurately as possible [4, 6]. These models usually result in large number of differential equations demanding heavy computational power. Thus, they are more suitable for offline system analysis and design rather than real-time control applications. The second group of models is developed in a more control-oriented way using either map-based method or linearized black-box models to characterize linearized dynamics [8, 9]. These models lack adaptability and cannot address the strong non-linearity introduced by the chemical reactions. With rapid growth in computational power, more algebraic and differential equations can be solved in real time. More physical and chemical details are introduced into control-oriented models to form the socalled grey-box models [7]. With reduced 1-D or 0-D reactor model and simplified kinetics, this group of models seeks balance between the accuracy provided by detailed models (white-box model) and the efficiency provided by black-box models.

Since the focus of our work is development of grey-box model for SCR, we present a brief review of the work done by other researchers in this area. Upadhyay and Nieuwstadt [10] developed a three-state $\left(\mathrm{NH}_{3}, \mathrm{NOx}\right.$, and storage) lumped parameter model for the purpose of control design. Devarakonda et al. [11] extended this three-state model to a four-state model by adding $\mathrm{NO}_{2}$. Hsieh and Wang [12] also used this type of model but with different set of reactions. Surenahalli et al. [13] used two storage sites to model the $\mathrm{NH}_{3}$ storage and implemented an extended Kalman filter for estimating internal states of a $\mathrm{SCR}$ rector using $\mathrm{NO}_{\mathrm{x}}$ and $\mathrm{NH}_{3}$ sensors. The reduced-order models used in the above references are of homogeneous/single-phase-type models where surface species concentrations are assumed to be equal to that of gas phase (i.e., kinetically controlled regime). It is well known that the reaction rates are controlled by external (i.e., fluid to wall) mass transfer at high temperatures, and hence, two-phase models are needed to accurately predict exit conversions in high temperature regions $[6,14]$. There are other attempts in developing grey-box models with different approaches which are reviewed by Yuan et al. [3]. However, instead of a continuous chain connecting detailed and grey-box models, present grey-box models are rather scattered links. Missing connections with detailed white-box models, the present grey-box models cannot take advantage of and adapt to new developments in detailed reactor and kinetic models.

In this work, a systematic methodology for the development of ECU capable grey-box models from detailed reactor models is proposed. We use this procedure to develop a greybox model of a SCR reactor. Since the grey-box model remains fundamental based, there are direct connections between lumped parameters (in grey-box models) and detailed parameters (in white-box models). This grey-box model also captures all of the main qualitative features of the detailed model. Additionally, a system identification procedure which uses detailed model to tune the grey-box model is proposed. The resulting model is then linearized around a certain operating point and an observer-based state feedback controller is developed. It is shown that the linearization within a certain operating range can produce an accurate control-oriented linear model and that the developed controller can improve the performance of the SCR reactor compared to a simple PID controller. 


\section{SCR Chemistry}

The SCR of NOx with $\mathrm{NH}_{3}$ has been studied in detail on various catalyst formulations. Two groups of SCR catalysts, namely vanadia- and zeolite-based, are widely used in the commercial after-treatment applications. The zeolite-based catalysts are proven to be active over a wide operating temperature range than the vanadia-based catalysts. The SCR chemistry on these catalyst formulations is investigated extensively in the literature, and it has been found that the set of key reactions presented in Table 1 are common to the above SCR catalysts [6]. Side reactions like formation of $\mathrm{NH}_{4} \mathrm{NO}_{3}$ and $\mathrm{N}_{2} \mathrm{O}$ are excluded in this work but can be easily included when necessary as these extra reactions do not pose any additional modeling difficulties. Ammonia adsorption reaction (R1) is a key step in the urea injection-based SCR reactors because the NOx reduction reactions depend on the adsorbed $\mathrm{NH}_{3}$. Ammonia oxidation reaction (R2) is an important side reaction which competes with NOx reduction reactions for stored $\mathrm{NH}_{3}$. $\mathrm{NO}$ oxidation reaction (R3) is a reversible reaction which is equilibrium limited at higher temperatures. The reaction (R4) between $\mathrm{NH}_{3}$ and $\mathrm{NO}$ is called standard SCR reaction and is the only NOx reduction reaction in the absence of $\mathrm{NO}_{2}$. The reaction (R5) involving $\mathrm{NH}_{3}$ and equimolar amounts of $\mathrm{NO}$ and $\mathrm{NO}_{2}$ is significantly faster than the standard SCR reaction at low temperature and hence called the fast $\mathrm{SCR}$ reaction. The last reaction (R6) is called $\mathrm{NO}_{2} \mathrm{SCR}$ reaction and is an important reaction when feed contains significant amounts of $\mathrm{NO}_{2}$. Generally, fast SCR reaction (R5) has the highest rate and is relatively more active at lower temperatures. The relative rates between the standard SCR (R4) and $\mathrm{NO}_{2}$ SCR (R6) reactions vary depending on operating conditions and catalyst formulation. Global reaction rate expressions used in this work are listed in Table 1 [6].

\section{Detailed Model}

The mathematical models of catalytic monoliths vary in complexity depending on the level of detail included. Figure 1 shows the overview of various physical and chemical processes occurring in a SCR reactor. The detailed models consist of coupled non-linear PDEs in at least two spatial dimensions and time along with highly non-linear reaction source/sink terms appearing in solid-phase species and energy balances. Although the numerical solution of these detailed models is possible with present-day computers, these are not practical when the objective is to explore the parameter space and conduct optimization studies. The most widely used simplified models of catalytic monoliths are the 1+1D (with one spatial direction in flow direction and the second spatial dimension along washcoat depth) and 1D (with one spatial direction in flow direction) two-phase models. These simplified models capture all the qualitative features of the monolith reactor, and the quantitative predictions are also accurate for all practical purposes [14]. In the $1+1 \mathrm{D}$ model, separate equation is used to resolve concentration gradients in the washcoat (i.e., captures the pore diffusion resistance) whereas in the 1D model, washcoat diffusional limitations are ignored or accounted by using the concept of effectiveness factor, internal mass transfer coefficient [15], or an asymptotic solution [16]. These two-phase models can be further simplified for different limiting cases, such as infinite/zero solid-phase conductivity, negligible gradients between fluid and solid-phases, or steadystate conditions [17]. It has been shown in several studies that the interphase gradients and washcoat diffusional limitations are important in the practical operating range of catalytic monoliths $[6,14,15]$. For this reason, the $1+1 \mathrm{D}$ model is used in this work. We use constant thermodynamic properties because the non-isothermal effects can be neglected when the heat of reaction is negligible, which is usually the case in the SCR reactor where the reactant concentrations in the feed are small $(\sim 500 \mathrm{ppm})$. Furthermore, the energy balances can be dropped in the steady-state cases but not in transient cases. For the transient simulations, solid temperature lags the fluid temperature because of large solid to fluid heat capacity ratio; hence, energy balances need to be used to get correct reaction rates in the solid phase.

The $1+1 \mathrm{D}$ model is described by the following equations: Species balances:

$$
\begin{aligned}
& \frac{\partial \boldsymbol{X}_{f m}}{\partial t}=-u \frac{\partial \boldsymbol{X}_{f m}}{\partial x}-\frac{\boldsymbol{k}_{m e}}{R_{\Omega}}\left(\boldsymbol{X}_{f m}-\left.\boldsymbol{X}_{w c}\right|_{y=0}\right), \\
& \varepsilon \frac{\partial \boldsymbol{X}_{w c}}{\partial t}=\frac{1}{C_{0}} \boldsymbol{v}^{T} \boldsymbol{r}+\boldsymbol{D}_{s} \frac{\partial^{2} \boldsymbol{X}_{w c}}{\partial y^{2}},
\end{aligned}
$$

Table 1 SCR reaction mechanism

\begin{tabular}{lll}
\hline Reaction number & Reaction & Rate expression \\
\hline R1 & $\mathrm{NH}_{3}+\mathrm{S} \Leftrightarrow \mathrm{NH}_{3} \mathrm{~S}$ & $\mathrm{R} 1=k_{f, 1} \cdot(1-\theta) \mathrm{X}_{\mathrm{NH} 3}-k_{b, 1} \cdot \theta$ \\
R2 & $2 \mathrm{NH}_{3} \mathrm{~S}+1.5 \mathrm{O}_{2} \rightarrow \mathrm{N}_{2}+3 \mathrm{H}_{2} \mathrm{O}+2 \mathrm{~S}$ & $\mathrm{R} 2=k_{f, 2} \cdot \theta \cdot \mathrm{X}_{\mathrm{O} 2}$ \\
$\mathrm{R} 3$ & $\mathrm{NO}+0.5 \mathrm{O}_{2} \Leftrightarrow \mathrm{NO}_{2}$ & $\mathrm{R} 3=k_{f, 3} \cdot \mathrm{X}_{\mathrm{NO}} \mathrm{X}_{\mathrm{O} 2} 0.5-k_{b, 3} \cdot \mathrm{X}_{\mathrm{NO} 2}$ \\
R4 & $4 \mathrm{NH}_{3} \mathrm{~S}+4 \mathrm{NO}+\mathrm{O}_{2} \rightarrow 4 \mathrm{~N}_{2}+6 \mathrm{H}_{2} \mathrm{O}+4 \mathrm{~S}$ & $\mathrm{R} 4=k_{f, 4} \cdot \theta \cdot \mathrm{X}_{\mathrm{NO}}$ \\
R5 & $2 \mathrm{NH}_{3} \mathrm{~S}+\mathrm{NO}+\mathrm{NO}_{2} \rightarrow 2 \mathrm{~N}_{2}+3 \mathrm{H}_{2} \mathrm{O}+2 \mathrm{~S}$ & $\mathrm{R} 5=k_{f, 5} \cdot \theta \cdot \mathrm{X}_{\mathrm{NO}} \mathrm{X}_{\mathrm{NO} 2}$ \\
R6 & $4 \mathrm{NH}_{3} \mathrm{~S}+3 \mathrm{NO}_{2} \rightarrow 3 \cdot 5 \mathrm{~N}_{2}+6 \mathrm{H}_{2} \mathrm{O}+4 \mathrm{~S}$ & $\mathrm{R} 6=k_{f, 6} \cdot \theta \cdot \mathrm{X}_{\mathrm{NO} 2}$ \\
\hline
\end{tabular}



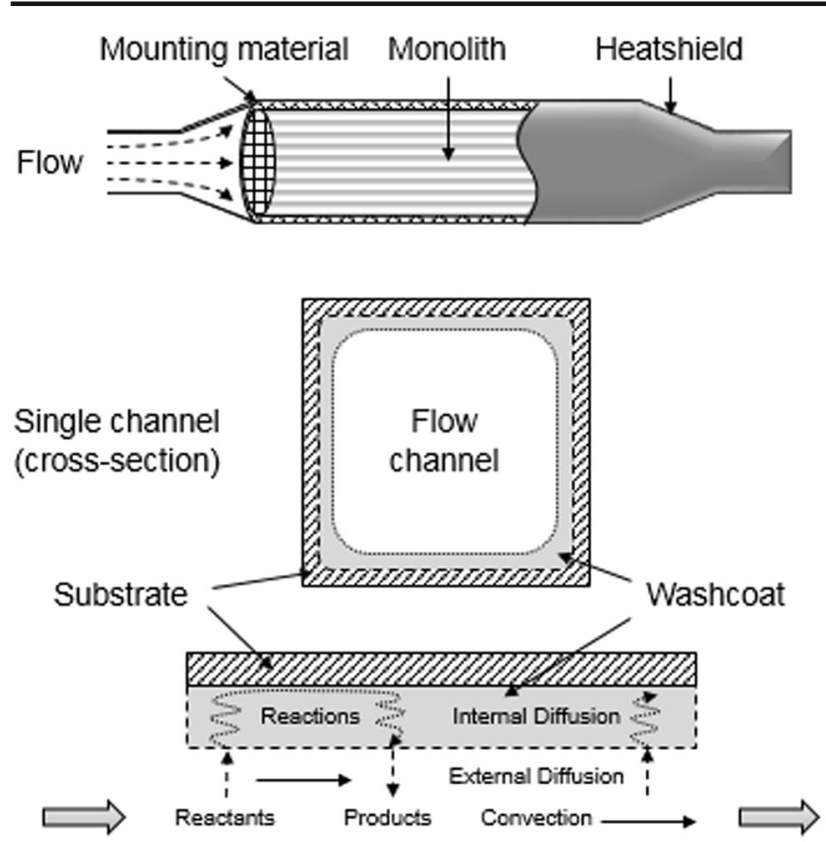

Feed Gas

Exhaust

Fig. 1 Overview of various physical and chemical processes occurring in a washcoated monolith channel

Energy balances:

$$
\begin{aligned}
& \rho_{f} C p_{f} \frac{\partial T_{f}}{\partial t}=-u \rho_{f} C p_{f} \frac{\partial T_{f}}{\partial x}-\frac{h}{R_{\Omega}}\left(T_{f}-T_{s}\right) \\
& \delta_{w} \rho_{w} C p_{w} \frac{\partial T_{s}}{\partial t}=\delta_{w} k_{w} \frac{\partial^{2} T_{s}}{\partial x^{2}}+h\left(T_{f}-T_{s}\right)+\delta_{c} \overline{\boldsymbol{r}}^{T}(-\boldsymbol{\Delta H}),
\end{aligned}
$$

Site balance:

$$
\frac{\partial \theta}{\partial t}=\frac{1}{C_{s}} \boldsymbol{\nu}_{\theta}^{T} \boldsymbol{r},
$$

Boundary conditions:

$$
\begin{aligned}
& \boldsymbol{X}_{f m}(t)=\boldsymbol{X}_{f m}^{i n} @ x=0, \\
& \boldsymbol{k}_{m e}\left(\boldsymbol{X}_{f m}-\boldsymbol{X}_{w c}\right)=-\boldsymbol{D}_{s} \frac{\partial \boldsymbol{X}_{w c}}{\partial y} @ y=0, \\
& \frac{\partial \boldsymbol{X}_{w c}}{\partial y}=0 @ y=\delta_{c}, \\
& T_{f}(t)=T_{f}^{i n}(t) @ x=0, \\
& \left.\frac{\partial T_{s}}{\partial z}\right|_{x=0}=\left.\frac{\partial T_{s}}{\partial z}\right|_{x=L}=0 .
\end{aligned}
$$

The variables used in the above equations are defined in the nomenclature section. Various correlations are available in the literature for calculating external heat $(h)$ and mass transfer coefficients $\left(\boldsymbol{k}_{\boldsymbol{m}}\right)$ as function of axial position. It was shown that when the transverse Peclet number $\left(P=\frac{u R_{\Omega}^{2}}{L D_{f}}\right)$ is less than 0.1 , flow conditions in the entry region of monolith have negligible effect on the exit conversion [18]. Thus, we neglect the entrance length effects in this work because transverse Peclet number is less than 0.1 for most of the monolith reactors used in the automotive after-treatment applications and use constant heat and mass transfer coefficients corresponding to a rounded square channel.

\section{Model Reduction}

Due to the limited computational capability of engine control unit (ECU) and hardware-in-loop (HIL) systems, it is not practical to solve detailed model equations on these systems in real time, and hence, there is a need for reduced-order models. Detailed $(1+1 \mathrm{D})$ model presented in the above section explicitly accounts for the washcoat diffusion and was calibrated against experimental data by Metkar et al. [6]. The 1+1D model consists of a system of stiff differential equations, and its solution requires sophisticated implicit solvers. The $1+1 \mathrm{D}$ model consists of total of nine PDEs if $\mathrm{NH}_{3}, \mathrm{NO}$, and $\mathrm{NO}_{2}$ species emissions need to be controlled. In this section, we systematically derive a reduced order model from the $1+1 \mathrm{D}$ model presented in previous section. First, 1 $+1 \mathrm{D}$ model is reduced to a 1D model by ignoring washcoat diffusion. Even though this seems like a strong assumption, this assumption implicitly lumps the washcoat diffusion effects into kinetics parameters. Diffusional effects alter the true activation energies of reactions, and the resulting activation energies are called apparent activation energies. It will be shown later that the consequences of this approximation can be handled through the parameter optimization. Next, the resulting 1D model is further simplified to a $0 \mathrm{D}$ model by ignoring axial gradients which is a reasonable assumption for high space velocities encountered in after-treatment applications. When this assumption is not satisfied, we can account for spatial variations by using the so-called continuously stirred tank reactors (CSTRs)-/blocks-in-series approach which will be discussed in detail in the later sections. Next, the accumulation in fluid phase is ignored leading to a so-called quasi steadystate approximation, which is very frequently used even in detailed models. With this assumption, the transient terms in fluid-phase species balances can be neglected. With the above three assumptions, $1+1 \mathrm{D}$ model simplifies to the following systems of equations:

$\frac{u}{L}\left(\boldsymbol{X}_{f m}-\boldsymbol{X}_{f m}^{i n}\right)+\frac{k_{m e}}{R_{\Omega}}\left(\boldsymbol{X}_{f m}-\boldsymbol{X}_{w c}\right)=0$,

$\frac{1}{C_{0}} \boldsymbol{\nu}^{T} \boldsymbol{r}+\frac{k_{m e}}{\delta_{c}}\left(\boldsymbol{X}_{f m}-\boldsymbol{X}_{w c}\right)=0$,

$\frac{u}{L}\left(T_{f}-T_{f}^{i n}\right)+\frac{h}{R_{\Omega} \rho_{f} C p_{f}}\left(T_{f}-T_{s}\right)=0$,

$\delta_{w} \rho_{w} C p_{w} \frac{d T_{s}}{d t}=h\left(T_{f}-T_{s}\right)$, 
$\frac{d \theta}{d t}=\frac{1}{C_{S}} \boldsymbol{\nu}_{\theta}^{T} \boldsymbol{r}$.

Expanding the above equations for $\mathrm{NH}_{3}, \mathrm{NO}$, and $\mathrm{NO}_{2}$ species, using the reactions listed in Table 1 , and rearranging the equations result in the following simplified systems of equations:

$$
\begin{aligned}
& X w_{N H 3}=\frac{F P P^{*} X_{N H 3}^{i n}+k_{b, 1} * \theta}{F P P+k_{\mathrm{f}, 1} *(1-\theta)}, \\
& X_{N H 3}^{\text {out }}=\frac{P^{*} X_{N H 3}^{\text {in }}+X w_{N H 3}}{1+P}, \\
& X w_{N O 2}=\frac{-b+\sqrt{b^{2}-4 a c}}{2 a}, \\
& X_{N O 2}^{\text {out }}=\frac{P^{*} X_{N O 2}^{\text {in }}+X w_{N O 2}}{1+P}, \\
& X w_{N O}=\frac{F P P^{*} X_{N O}^{i n}+k_{b, 3} * X w_{N O 2}}{F P P+k_{f, 3} X_{O 2}^{0.5}+4 k_{\mathrm{f}, 4} * \theta+k_{\mathrm{f}, 5} \theta^{*} X w_{N O 2}}, \\
& X_{N O}^{\text {out }}=\frac{P^{*} X_{N O}^{i n}+X w_{N O}}{1+P}, \\
& T_{f}^{\text {out }}=\frac{T_{f}^{\text {in }}+\frac{h L T_{s}}{u R_{\Omega} \rho_{f} C p_{f}}}{1+\frac{h L}{u R_{\Omega} \rho_{f} C p_{f}}}, \\
& C_{s} \frac{d \theta}{d t}=R 1-2 R 2-4 R 4-2 R 5-4 R 6 \\
& \delta_{w} \rho_{w} C p_{w} \frac{d T_{s}}{d t}=\frac{h\left(T_{f}^{i n}-T_{s}\right)}{1+\frac{h L}{u R_{\Omega} \rho_{f} C p_{f}}}, \\
& w h
\end{aligned}
$$

where

$$
\begin{aligned}
& P=\frac{u R_{\Omega}}{L k_{m e}} \\
& F P P=\frac{C_{\text {total }} * k_{m e}}{\delta_{c}} \frac{P}{1+P} \\
& a=F P P^{*} k_{\mathrm{f}, 5} * \theta+2 k_{b, 3} * k_{\mathrm{f}, 5} * \theta+3 * k_{\mathrm{f}, 5} * k_{\mathrm{f}, 6} * \theta^{2}, \\
& b=F P k_{\mathrm{f}, 5}^{*} \theta^{*}\left(X_{N O}^{i n}-X_{N O 2}^{i n}\right)-k_{f, 3} * k_{b, 3} * X_{O 2}^{0.5} \\
& +\left(F P P+k_{b, 3}+3 k_{\mathrm{f}, 6} * \theta\right)\left(F P P+k_{f, 3} X_{O 2}^{0.5}+4 k_{4, \mathrm{f}} * \theta,\right. \\
& c=-F P P^{*} X_{N O 2}^{i n}\left(F P P+k_{f, 3} * X_{O 2}^{0.5}+4 k_{4, \mathrm{f}} * \theta\right)-F P P^{*} k_{f, 3} * X_{O 2}^{0.5} X_{N O}^{i n} .
\end{aligned}
$$

In the above equations, internal states of the system are represented by coverage fraction $(\theta)$ and solid temperature $\left(T_{\mathrm{S}}\right)$, and all other variables are expressed with an algebraic function of these two states. The above two ordinary differential equations (ODEs) (Eqs. 23 and 24) can be converted into algebraic equations by using the explicit difference schemes such as Euler or Runge-Kutta methods. For example, using an explicit Euler method, the two ODEs can be converted into the following algebraic equations;

$\theta_{s}(t+\Delta t)=\theta_{s}(t)+\frac{\Delta t}{C_{s}}(R 1-2 R 2-4 R 4-2 R 5-4 R 6)$,

$$
T_{s}(t+\Delta t)=T_{s}(t)+\frac{\Delta t}{\delta_{w} \rho_{w} C p_{w}}\left(\frac{h\left(T_{f}^{i n}-T_{s}(t)\right)}{1+\frac{h L}{u R_{\Omega} \rho_{f} C p_{f}}}\right) .
$$

\section{Grey-Box Model Setup}

The grey-box model presented in the previous section is a second-order system (i.e., contains two first-order ODEs). When there are steep gradients in the axial direction in coverage and/or solid temperature, it will be necessary to use higher-order system of equations to accurately model the system dynamics. We use the so-called CSTRs-/blocks-in-series approach to capture the spatial gradients. Figure 2 shows the schematic of a CSTRs-/blocks in-series approach. Output signals from one CSTR are fed to the next CSTR in the downstream as input signals. Number of states/order of the system is equal to two times the number of CSTRs. Number of CSTRs can be considered as optimization parameter if necessary. From the grey-box model equations presented in the previous section, we can see that grey-box model preserves the physical parameters of the detailed model. The grey-box model predictions are satisfactory even with original kinetic parameter values. Model accuracy increases with inclusion of additional CSTRs. However, retuning of parameters is necessary to increase accuracy level without sacrificing computational load. In the next section, the system identification/ parameter tuning process is explained in detail.

\section{System Identification}

The first step in the system identification process is the calibration of detailed model. Figure 3 shows the scheme of the workflow of detailed model calibration. In general, detailed models are calibrated to experimental measurements which are obtained by following a test protocol. Test protocols are designed to excite different states of the system and are designed to understand the physics of the system [19]. In this work, we have not calibrated the 1 +1D model but, instead, used the parameter values reported in [6] in which the $1+1 \mathrm{D}$ model was calibrated to the measurements taken on $\mathrm{Cu}$ chabazite and Fe-ZSM-5 catalysts. The $1+1 \mathrm{D}$ model can be solved using well-known openly available ODE solver packages like LSODE, SUNDIALS, etc. or commercial software packages like GT-SUITE and MATLAB. MATLAB is used to solve $1+1 \mathrm{D}$ model since rest of the system identification process is carried out in MATLAB. Metkar et al. [6] found that using 21 points in the flow direction and 10 points along the washcoat depth is sufficient to get grid independent solution. This gives the axial discretization length of $1 \mathrm{~mm}$. We 


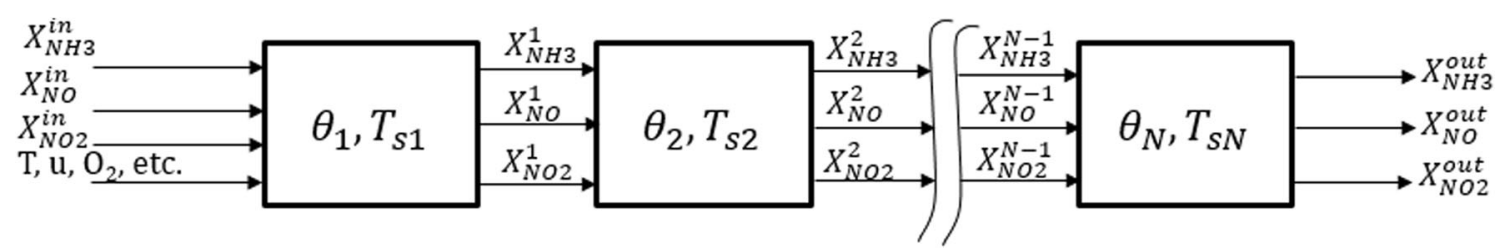

Fig. 2 Schematic of grey-box model set-up

confirmed that the 1-mm axial discretization length gives gridindependent solution and use this in all of the simulations carried out in this work.

As shown in the above sections, grey-box model remains fundamental based and contains same model parameters as the $1+1 \mathrm{D}$ model. In the model reduction process, some physical processes (like pore diffusion effects, accumulation in fluid phase, etc.) are omitted or lumped into other parameters to reduce the computational burden. Therefore, it is necessary to tune/optimize the grey-box model parameters to improve the accuracy. Figure 3 shows the scheme of the workflow of grey-box model tuning process. The main difference between the calibration of detailed and grey-box model is the input signal design. Input signals used in the detailed model calibration are dictated by test protocols whereas input signals for the grey-box model calibration need to be carefully designed. They must be "rich" in their frequency content so that the dynamic system can be identified properly. In addition, the selection of the right frequency range is also important; this is why prior knowledge of the bandwidth of the plant is required. Signals which are often used in identification and are rich in frequencies include random signals. In particular, pseudo-random binary sequences or super-imposed sinusoidal signals are often used in identification. In this paper, System Identification Toolbox from The MathWorks is used to generate input signals. Specifically, the "idinput" function provides several options for generating input signals-random Gaussian signal (rgs), random binary signal (rbs), sine, etc. Continuous signals are preferred since the grey-box model is continuous-time-based model. We generated input signals using "sine" option which gives a signal that is some of sinusoids of different frequencies. The frequency contents of the signal are determined by the lower and upper bound of the passband. Same input signals are fed to both $1+1 \mathrm{D}$ and greybox models. Kinetic parameters in grey-box model are tuned to match the prediction of detailed model. MATLAB System Identification Toolbox is used for optimization. Kinetic parameters are tuned for each of the reactions separately as explained in the following sections.

\section{1 $\mathrm{NH}_{3}$ Adsorption and Desorption}

Ammonia adsorption is key step in the urea injection-based SCR reaction system as most of the NOx reduction reactions depend on the stored $\mathrm{NH}_{3}$. Hence, it is important to predict the $\mathrm{NH}_{3}$ storage accurately. Typically, temperature programmed desorption (TPD) experiments are used to understand the $\mathrm{NH}_{3}$ storage dynamics. Figure 4 shows the typical TPD experiment inputs and outputs. In TPD experiments, a feed consisting of $\mathrm{NH}_{3}$ (less than $0.1 \%$ ) and inert gas is introduced into the reactor until saturation where outlet $\mathrm{NH}_{3}$ is equal to inlet $\mathrm{NH}_{3}$. Feed temperature is kept constant during this adsorption phase. After this saturation phase, $\mathrm{NH}_{3}$ in the feed is cutoff and only inert gas is introduced into the system. Some of the physisorbed $\mathrm{NH}_{3}$ desorbs during this post uptake period and leaves the reactor. After this period, inlet gas temperature is increased gradually at rate of about $10 \mathrm{~K} / \mathrm{min}$. Ammonia desorbs from the catalyst surface and exits the reactor during this temperature ramp period. Detailed model is fitted to the TPD data to determine the kinetic parameters of adsorption and desorption reaction $(\mathrm{R} 1)$.

As explained in the above section, TPD experiments are useful to understand system behavior and calibrate detailed models but not ideal for tuning the grey-box model in which
Fig. 3 Workflow of system identification process

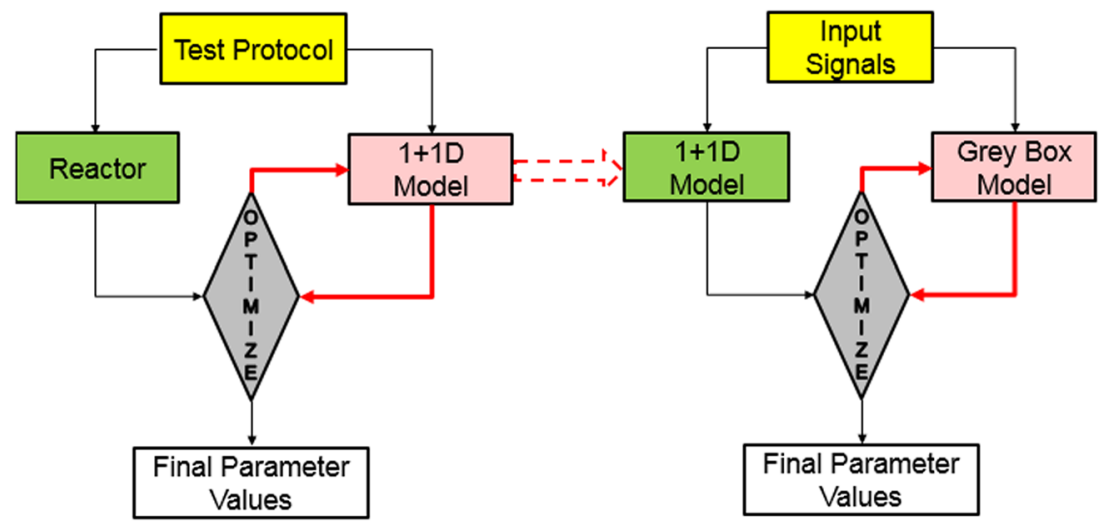



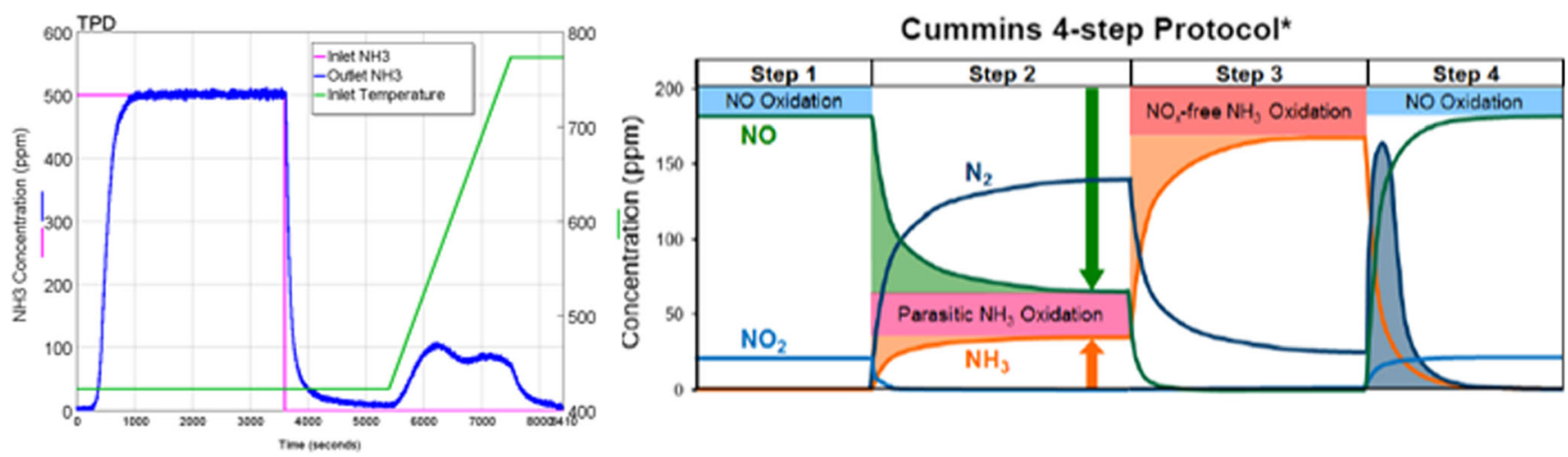

Fig. 4 Typical type of experimental studies used in calibrating detailed models [6, 19]

some of the system details are lumped. Input signals in TPD are static for most of the time whereas we need persistently excited input signals for grey-box model tuning. Space velocity of $57,000 \mathrm{~h}^{-1}$ at STP is used in the tuning of grey-box model, but varying space velocity (representing New European Drive Cycle (NEDC)) is used in the model validation section. The persistently excited signals used for inlet $\mathrm{NH}_{3}$ concentration and inlet temperature are shown in Fig. 5, which also shows the comparison of outlet $\mathrm{NH}_{3}$ from both the models. We can see that the grey-box model accurately captures the dynamics of the $\mathrm{NH}_{3}$ storage with rootmean-square error (RMSE) error for outlet $\mathrm{NH}_{3}$ of $19 \mathrm{ppm}$. The retuned parameter values are given in Table 2, and these values are kept constant in subsequent parameter tuning of other SCR reactions. It is worth noting that when tuning $\mathrm{NH}_{3}$ adsorption and desorption rate parameters, the adsorption activation energy $\left(E_{\mathrm{f}, 1}\right)$ is set to zero because ammonia adsorption process can be adequately modeled using a simple collision theory and, as such, it does not involve any activation
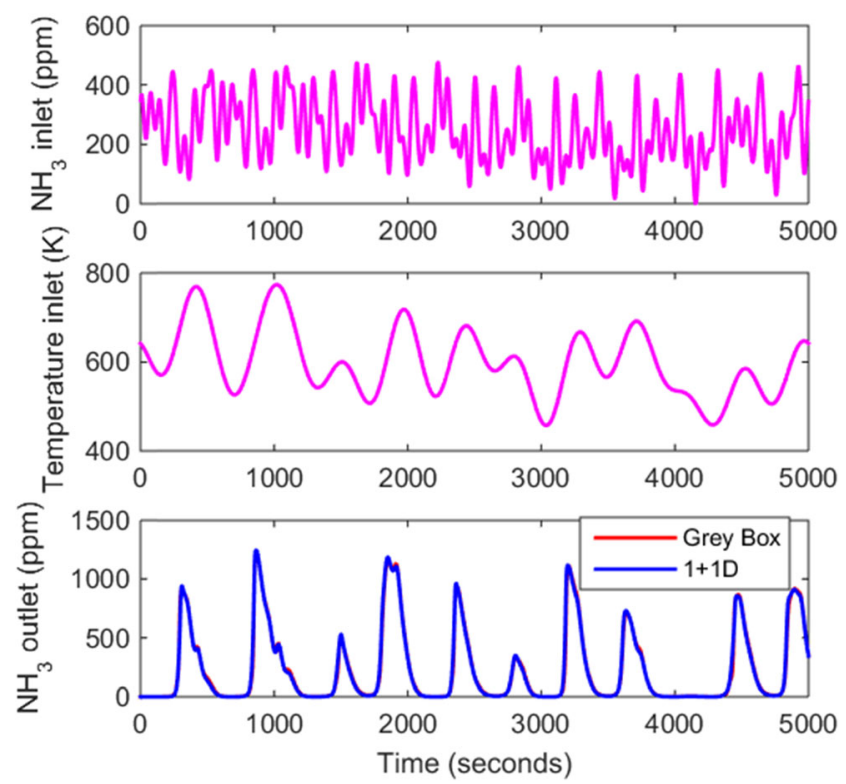

Fig. 5 Tuning of $\mathrm{NH}_{3}$ adsorption-desorption step: a inlet $\mathrm{NH}_{3}$ signal, b inlet temperature, and $\mathbf{c}$ predicted $\mathrm{NH}_{3}$ outlet concentration energy barrier. Thus, it is a commonly accepted practice [6] to set the activation energy to zero for the absorption process while leaving the desorption process activated.

\subsection{Ammonia Oxidation}

Ammonia oxidation is an important side reaction which competes with $\mathrm{NOx}$ reduction reactions for stored $\mathrm{NH}_{3}$. For this case, inlet feed consisting of $\mathrm{NH}_{3}$ and $\mathrm{O}_{2}$ is fed to both the $1+$ $1 \mathrm{D}$ and grey-box models. $\mathrm{NH}_{3}$ inlet concentration varies between 0 and $500 \mathrm{ppm}$, and inlet temperature varies between 473 and $723 \mathrm{~K}$. Inlet concentration of $\mathrm{O} 2$ is fixed at $5 \%$. Kinetics parameters of reaction R2 are tuned in this step, and the optimized values are provided in Table 2. As shown in Fig. 6, grey-box model accurately matches the outlet $\mathrm{NH}_{3}$ of detailed model with RMSE of 15 ppm.

\subsection{NO Oxidation}

The oxidation of $\mathrm{NO}$ to $\mathrm{NO}_{2}$ is an important reaction because of its role in fast SCR reaction (R5). NO oxidation is a reversible reaction which is equilibrium limited at high temperatures. For this case, inlet feed consisting of $\mathrm{NO}$ and $\mathrm{O}_{2}$ is used. As shown in Fig. 7, inlet NO concentration varies between 0 and $250 \mathrm{ppm}$ and inlet temperature varies between 373 and $873 \mathrm{~K}$. Inlet concentration of $\mathrm{O}_{2}$ is fixed at $5 \%$. Pre-exponent multiplier and activation energy for forward reaction R3 are tuned in this step, and optimized values are provided in Table 2. Reverse reaction rate constant is calculated using the equilibrium constant. As shown in Fig. 7, grey-box model accurately matches $1+1 \mathrm{D}$ model predictions for outlet $\mathrm{NO}$ and $\mathrm{NO}_{2}$ with RMSE of 3 and $0.5 \mathrm{ppm}$, respectively.

\subsection{Standard SCR Reaction}

Standard SCR reaction (R4) refers to the reaction between $\mathrm{NH}_{3}$ and $\mathrm{NO}$, with the participation of $\mathrm{O} 2$. For this case, inlet feed consisting of $\mathrm{NH}_{3}, \mathrm{NO}$, and $\mathrm{O}_{2}$ is fed to both the models. As shown in Fig. 8, $\mathrm{NH}_{3}$ and $\mathrm{NO}$ concentrations vary between 
Table 2 Optimized kinetic parameter values

\begin{tabular}{llllll}
\hline Parameter name & $\begin{array}{l}\text { Numerical value } \\
\left(\mathrm{mol} / \mathrm{m}^{3} \text { washcoat s }\right)\end{array}$ & Parameter name & \multicolumn{2}{l}{$\begin{array}{l}\text { Numerical value } \\
(\mathrm{kJ} / \mathrm{mol})\end{array}$} \\
\hline & Grey-box & $1+1 \mathrm{D}$ & & Grey-box & $1+1 \mathrm{D}$ \\
$A_{\mathrm{f}, 1}$ & $5.68 \mathrm{e} 5$ & $6.68 \mathrm{e} 5$ & $E_{\mathrm{f}, 1}$ & 0 & 0 \\
$A_{\mathrm{b}, 1}$ & $4 \mathrm{e} 13$ & $4 \mathrm{e} 13$ & $E_{\mathrm{b}, 1}$ & 145.9 & 145.9 \\
$A_{\mathrm{f}, 2}$ & $5.36 \mathrm{e} 16$ & $5.56 \mathrm{e} 16$ & $E_{\mathrm{f}, 2}$ & 178.8 & 178.8 \\
$A_{\mathrm{f}, 3}$ & $4.66 \mathrm{e} 7$ & $5.1 \mathrm{e} 7$ & $E_{\mathrm{f}, 3}$ & 56 & 56 \\
$A_{\mathrm{f}, 4}$ & $6.57 \mathrm{e} 13$ & $7.08 \mathrm{e} 13$ & $E_{\mathrm{f}, 4}$ & 89.1 & 89.1 \\
$A_{\mathrm{f}, 5}$ & $1 \mathrm{e} 18$ & $1 \mathrm{e} 18$ & $E_{\mathrm{f}, 5}$ & 76.9 & 77.1 \\
$A_{\mathrm{f}, 6}$ & $1.82 \mathrm{e} 17$ & $1.96 \mathrm{e} 17$ & $E_{\mathrm{f}, 6}$ & 136 & 136.3 \\
\hline
\end{tabular}

0 to 500 ppm, and $\mathrm{O}_{2}$ concentration is set at $5 \%$. Fast (R5) and $\mathrm{NO}_{2}$ (R6) reactions are turned off, and kinetics parameters of reaction $\mathrm{R} 4$ are tuned. Figure 8 shows the comparison of outlet $\mathrm{NH}_{3}, \mathrm{NO}$, and $\mathrm{NO}_{2}$ concentrations from both the models, and as seen, the grey-box model predictions are accurate with RMSE of 6, 7, and 4 ppm, respectively.

\subsection{Fast and $\mathrm{NO}_{2} \mathrm{SCR}$ Reactions}

Reaction $\mathrm{R} 5$ involving $\mathrm{NH}_{3}$ and an equimolar amounts of $\mathrm{NO}$ and $\mathrm{NO}_{2}$ is significantly faster than the standard SCR reaction at low temperature and hence called fast SCR reaction. To take advantage of this fast reaction, in practice, an oxidation catalyst like DOC located upstream of SCR reactor could convert a fraction of $\mathrm{NO}$ to $\mathrm{NO}_{2}$ to maintain optimum $\mathrm{NO}_{2} / \mathrm{NOx}$ ratio of 0.5 . The last reaction $\mathrm{R} 6$, called $\mathrm{NO}_{2} \mathrm{SCR}$ reaction, is an important reaction when the feed contains significant amount of $\mathrm{NO}_{2}$. The excess amounts of $\mathrm{NO}_{2}$ in the feed mixture may
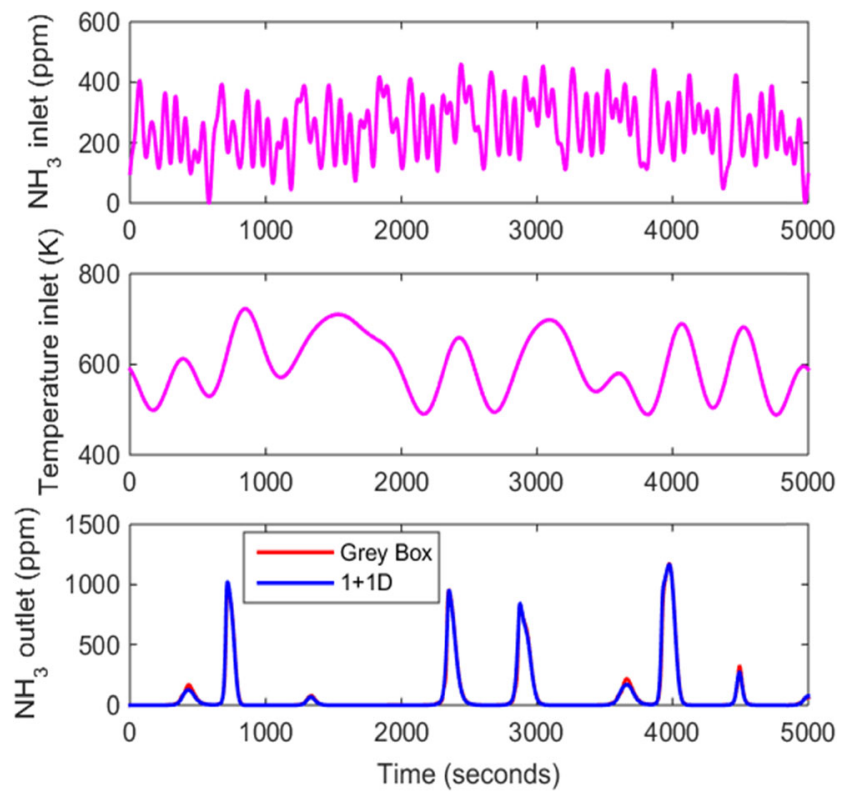

Fig. 6 Tuning of $\mathrm{NH}_{3}$ oxidation step: a inlet $\mathrm{NH}_{3}$ signal, b inlet temperature, and $\mathbf{c}$ predicted $\mathrm{NH}_{3}$ outlet concentration result in the formation of undesired products such as $\mathrm{NH}_{4} \mathrm{NO}_{3}$ and $\mathrm{N}_{2} \mathrm{O}$, but we do not consider these side reaction routes in this work. To tune the kinetic parameters of reactions $\mathrm{R} 5$ and R6, gas mixture consisting of $\mathrm{NH}_{3}, \mathrm{NO}, \mathrm{NO}_{2}$, and $\mathrm{O}_{2}$ is fed to both the models. As shown in Fig. 9, $\mathrm{NH}_{3}$ varies from 0 to $500 \mathrm{ppm}$ and $\mathrm{NO}$ and $\mathrm{NO}_{2}$ vary from 0 to $250 \mathrm{ppm}$. It can be seen from Fig. 9 that the grey-box model accurately matches the outlet concentrations of $\mathrm{NH}_{3}, \mathrm{NO}$, and $\mathrm{NO}_{2}$ of $1+1 \mathrm{D}$ model with RMSE of $0.6,4$, and 4 ppm, respectively.

\subsection{Model Validation}

The final step in the system identification process is the validation of model with different set of data than the data used to tune the grey-box model. Recently, Brown et al. [20] used the
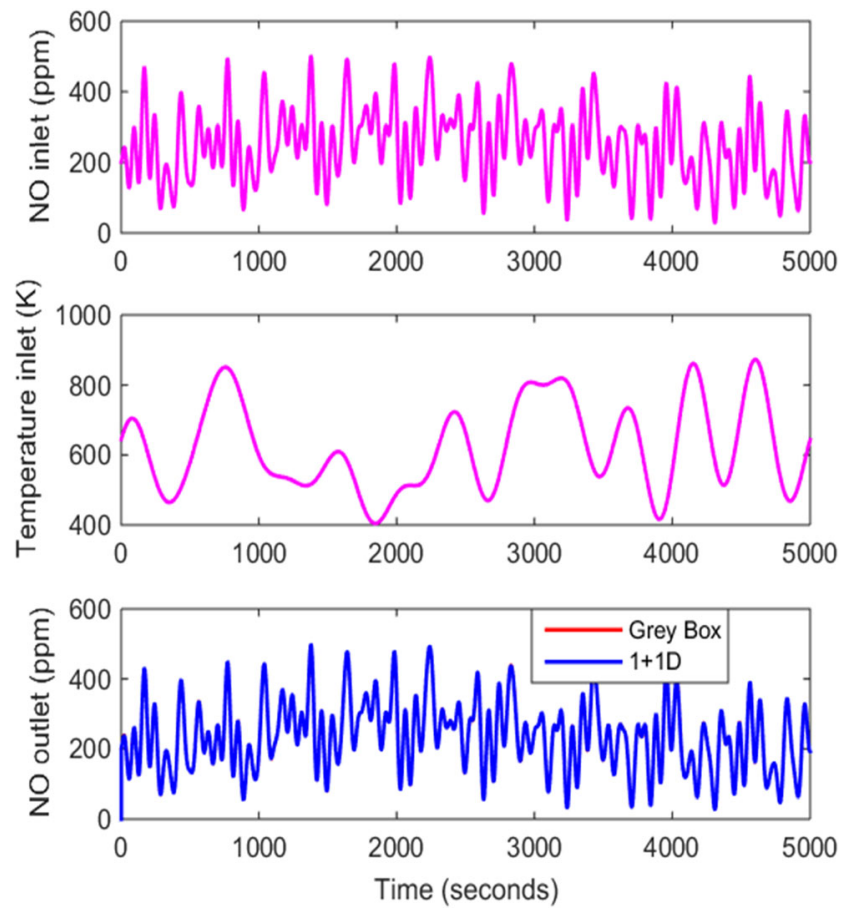

Fig. 7 Tuning of NO oxidation step: a inlet NO signal, b inlet temperature, and $\mathbf{c}$ predicted $\mathrm{NO}$ outlet concentration 

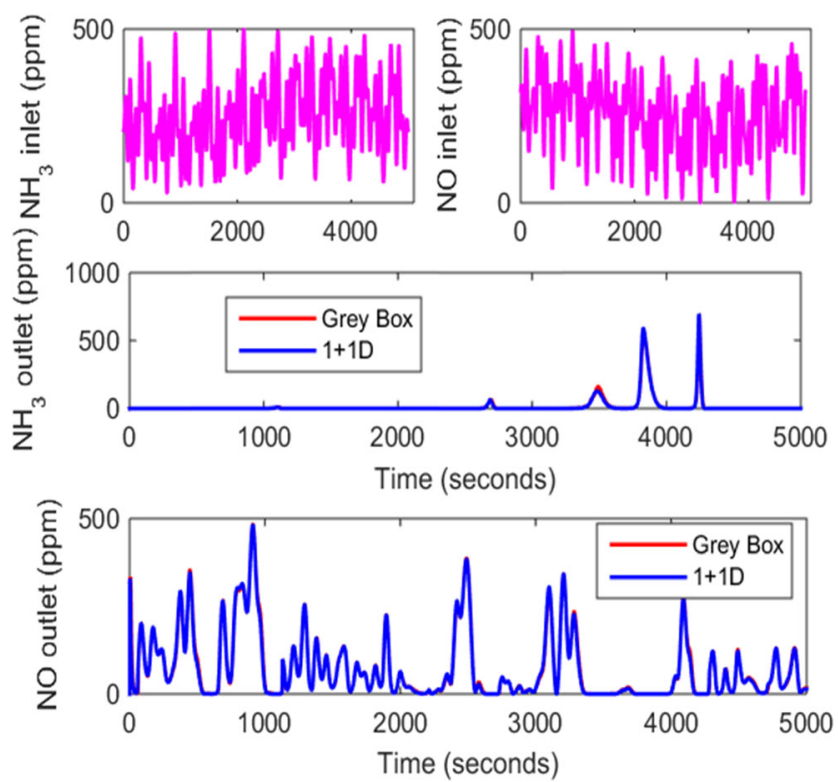

Fig. 8 Tuning of standard SCR reaction step: a inlet $\mathrm{NH}_{3}$ signal, b predicted $\mathrm{NH}_{3}$ outlet concentration, and c predicted $\mathrm{NO}$ outlet concentration

integrated engine + DOC + SCR system model of a $2.0-\mathrm{L}$ European diesel engine to study the deNOx performance of different SCR technologies during NEDC. We obtained the SCR inlet conditions from this work. Figure 10 shows inlet velocity, temperature, and species concentrations used in the NEDC simulation, and Table 2 lists kinetic parameters used in the grey-box model. Figure 11 compares the outlet $\mathrm{NH}_{3}, \mathrm{NO}$, and $\mathrm{NO}_{2}$ concentrations from both the models. It can be seen that the grey-box model predictions are close to that of $1+1 \mathrm{D}$
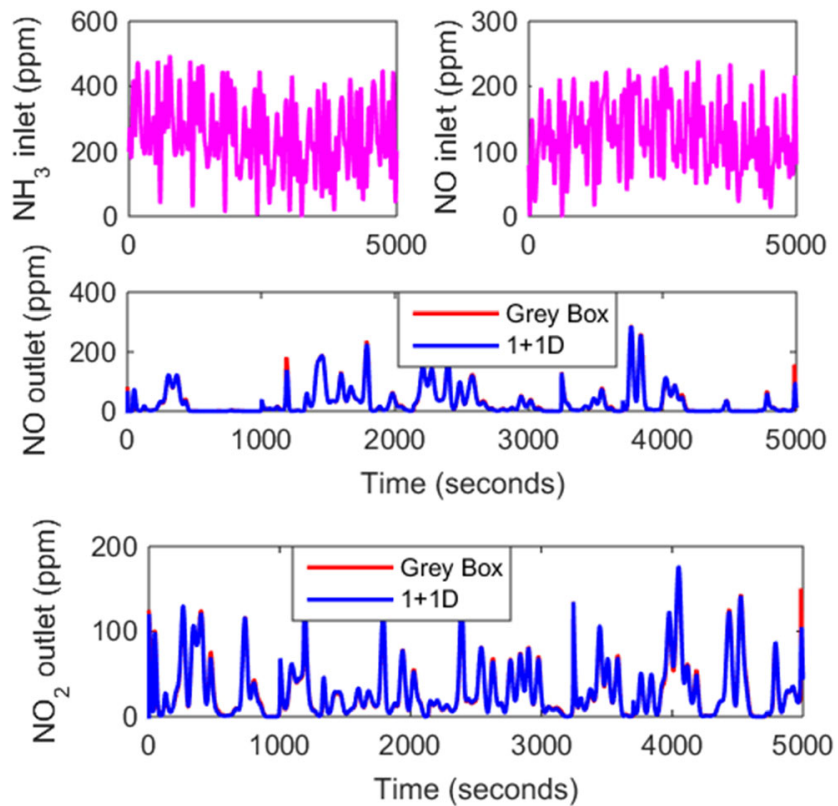

Fig. 9 Tuning of fast and $\mathrm{NO}_{2} \mathrm{SCR}$ reaction steps: $\mathbf{a}$ inlet $\mathrm{NH}_{3}$ and $\mathrm{NO}$ signals, b predicted $\mathrm{NO}$ outlet concentration, and $\mathbf{c}$ predicted $\mathrm{NO}_{2}$ outlet concentration model with RMSEs of $0.3,9$, and $2.5 \mathrm{ppm}$ for $\mathrm{NH}_{3}, \mathrm{NO}$, and $\mathrm{NO}_{2}$ outlet concentrations, respectively. Note that the $\mathrm{NH}_{3}$ break through at around $1100 \mathrm{~s}$ is not accurately captured by the grey-box model. Although this can be improved by using more CSTRs, it is not necessary to improve the accuracy in this case because $\mathrm{NH}_{3}$ break-through concentration is below the 10-ppm limit currently followed by OEMs and is also below the 10-ppm limit set by Euro VI standards [3]. It is worth mentioning that the grey-box model predictions for average $\mathrm{NH}_{3}$ storage fraction and average solid temperature agree well with that of $1+1 \mathrm{D}$ model.

\section{Computational Time}

Due to the limited computational resources available on ECU and HIL systems, it is crucial that the embedded model runs in real time. In this section, we compare the CPU time of $1+1 \mathrm{D}$ and grey-box models. Table 3 lists CPU times needed to simulate $1180 \mathrm{~s}$ of NEDC with different modeling approaches. Figure 10 shows inlet velocity, temperature, and species concentrations used in the NEDC simulation. Both $1+1 \mathrm{D}$ and grey-box models are solved in MATLAB using the ode15s solver which is a variable order multistep solver (i.e., needs the solutions at several preceding time points to compute current solution) based on numerical/backward differentiation formulas. Note that the grey-box model equations can also be solved using an explicit ODE solver whereas implicit ODE solver was required to solve $1+1 \mathrm{D}$ model due to stiff system of equations. Table 3 lists the CPU time to simulate the grey-box model with the ode 45 solver which is based on an explicit Runge-Kutta and is a one-step solver (i.e., needs only the solution at the immediately preceding time point to compute current solution). It can be seen from Table 3 that the grey-box model is orders of magnitude faster than $1+1 \mathrm{D}$ model. For comparison, we also showed CPU time with GTSUITE's Advanced Adaptive (AA) solver which uses an adaptive mesh in the axial direction and an adaptive time step to adjust to the demands of the moving reaction fronts [21]. AA solver accounts for the pore diffusional limitations using an asymptotic approach [16]. It can be seen that AA solver runs significantly faster than the $1+1 \mathrm{D}$ model but is slower than the grey-box model. We note that the grey-box model can run even faster if it is coded in compiled languages like $\mathrm{C}$ or FORTRAN. Figure 12 shows how the real time (RT) factor for both implicit (ode15s) and explicit (ode45) ODE solvers varies with number of CSTRs. Here, the RT factor is defined as real time divided by CPU time. It can be seen that RT factor reduces almost linearly with number of blocks. Implicit solver is slower than the explicit solver due to overhead associated with solving linear set of implicit algebraic equations at each time step. Note that the CPU time for one CSTR is higher than that of two CSTRs. This might be due to the overhead 
Fig. 10 Inlet velocity, temperature, and species concentrations used in the NEDC simulation
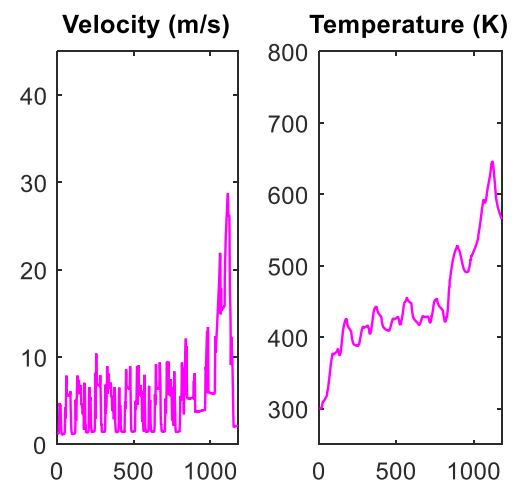
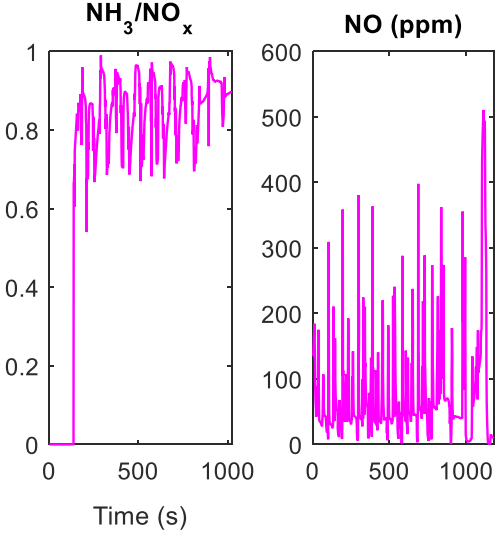

$\mathrm{NO}_{2}$ (ppm)

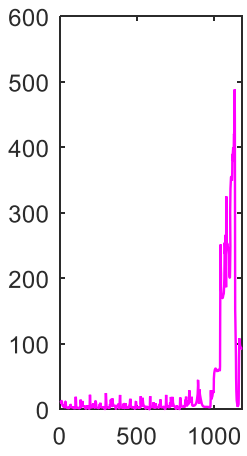

(variable allocation, memory management, etc.) associated with the first call to ODE solver. It is important to keep the CPU time per time step constant on ECU and HIL system to avoid overruns, and hence, fixed-step solvers are commonly used on these systems. The grey-box model can be solved using these fixed-step solvers. Furthermore, the grey-box model requires less computational resources than the detailed models.

\section{Control Applications}

As mentioned previously, the grey-box model contains a small number of non-stiff equations which means that it can be easily used in real-time applications. One more attractive property of this model is that the equations are in such a form that they can be linearized without much effort. The accuracy of linear models is limited to a small area around the operating point that the linearization took place, but they are useful for control design. This approach is attractive mostly due to the
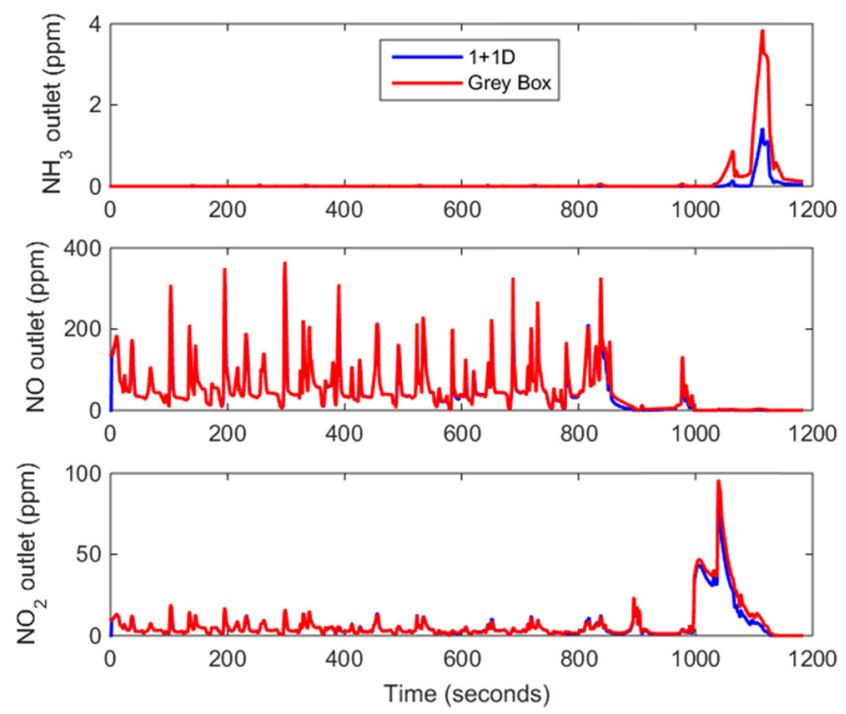

Fig. 11 Comparison of outlet species concentrations predicted by greybox and $1+1 \mathrm{D}$ models in NEDC simulation simplicity of implementation as well as the abundance of theoretical tools for analysis and synthesis. In order to overcome the accuracy limitation, the methodology can be extended to produce multiple piecewise linear plant models in order to cover the entire operating range of the SCR. In such a case, the controller algorithm performs the following main steps at each sample: (i) identifies the active linear model based on the values of the exogenous input signals, (ii) measures outputs and estimates the states using a state observer for the selected linear model, and (iii) calculates the control law that has been designed for the specific operating area. In the remainder of this section, we demonstrate the linearization of the model around a single operating point and the design of a control law based on the linear model.

Since the only control input is urea, the SCR model in its linear state space form is written as follows:

$\dot{\boldsymbol{X}}=\boldsymbol{A} \cdot \boldsymbol{X}+\boldsymbol{B} \cdot u+\boldsymbol{B}_{\boldsymbol{d}} \cdot \boldsymbol{W}$,

$\boldsymbol{Y}=\boldsymbol{C} \cdot \boldsymbol{X}+\boldsymbol{D} \cdot u+\boldsymbol{D}_{\boldsymbol{d}} \cdot \boldsymbol{W}$,

where

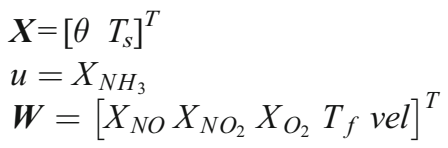

$A, B, B_{d}, C, D, D_{d}$ is the state vector, is the controlled input, is the exogenous input vector, which is considered as disturbance, are properly sized constant matrices.
Table 3 Run times with different solvers

\begin{tabular}{lll}
\hline Model & $\begin{array}{l}\text { Implicit } \\
\text { solver (s) }\end{array}$ & $\begin{array}{l}\text { Explicit } \\
\text { solver (s) }\end{array}$ \\
\hline GT-SUITE(21 volumes) AA solver & 4.1 & - \\
$1+1 D$ (21 + 10 volumes) MATLAB & 349.5 & - \\
Grey-box (21 volumes) MATLAB & 1.62 & 1.13 \\
Grey-box (1 volume) MATLAB & 0.82 & 0.48 \\
\hline
\end{tabular}




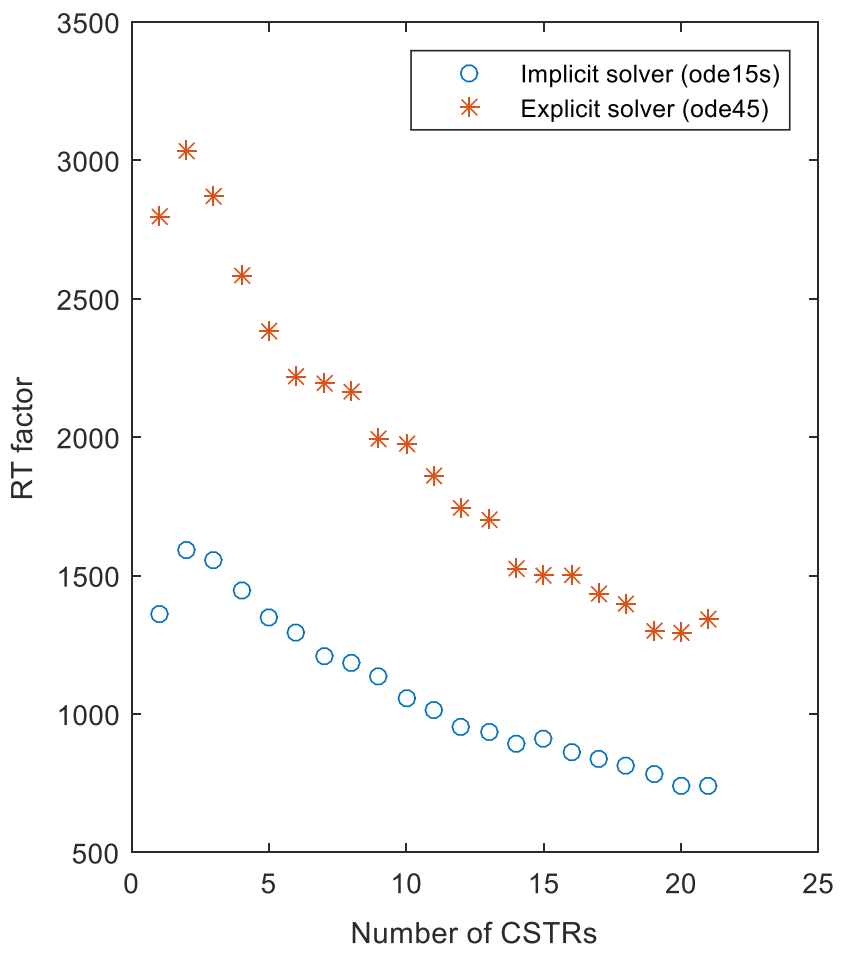

Fig. 12 RT factor with different number of CSTRs

Without loss of generality, we choose to linearize the model around the following operating point because this combination is close to the average values seen in a typical NEDC cycle:

$\boldsymbol{X}=\left[\begin{array}{ll}0 & 300\end{array}\right]^{T}$,

$u=100$,

$\boldsymbol{W}=\left[\begin{array}{lllll}100 & 100 & 150000 & 500 & 5\end{array}\right]^{T}$

The comparison on the frequency domain between the grey-box model and the linear model is depicted in Fig. 13 which shows very good agreement between the two models. The frequency test was performed with a varying sinusoidal input of amplitude $10 \mathrm{ppm}$. With the linear model at hand, we design an observer-based state feedback controller. Specifically, a closed-loop state estimator can be written as follows:

$\dot{\boldsymbol{X}}=\boldsymbol{A} \cdot \boldsymbol{X}+\boldsymbol{B} \cdot u+\boldsymbol{L}^{*}(\boldsymbol{y}-\boldsymbol{C} \cdot \boldsymbol{X}-\boldsymbol{D} \cdot \boldsymbol{U})$

where $\boldsymbol{L}$ is the observer gain. From the equation above, it is clear that the stability of the observer depends on the eigenvalues of $\boldsymbol{A}-\boldsymbol{L} \boldsymbol{C}$; therefore, proper choice of $\boldsymbol{L}$ guarantees a stable observer.

The control law can then be written as follows:

$U=-\boldsymbol{K}_{\boldsymbol{s}} \cdot \boldsymbol{X}+K_{N O} \cdot X_{N O}+K_{N_{2}} \cdot X_{N_{2}}$,

where $\boldsymbol{K}_{\boldsymbol{s}}, \boldsymbol{K}_{\boldsymbol{N} \boldsymbol{O}}$, and $\boldsymbol{K}_{\boldsymbol{N} \boldsymbol{O}_{2}}$ are the state feedback gain, the $\mathrm{NO}$ output feedback gain, and the $\mathrm{NO}_{2}$ output feedback gain, respectively.
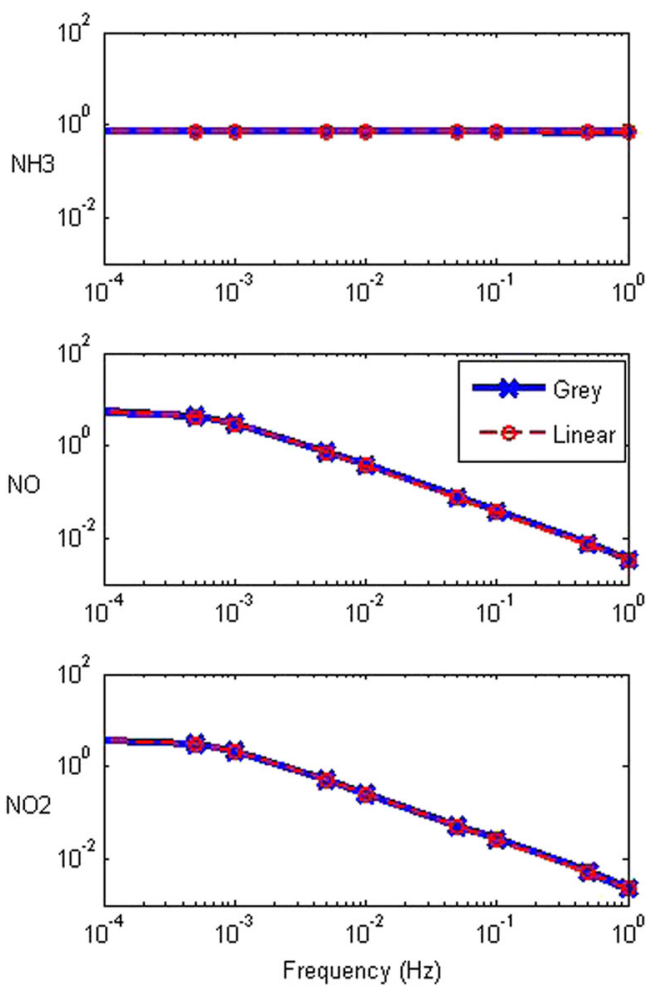

Fig. 13 Magnitude Bode plot comparison between grey-box and linear models on the frequency domain

The use of the state in the control law is very important. It essentially penalizes excessive or insufficient coverage inside the reactor, thus offsetting the dosing to lower or higher quantities, respectively. This allows the use of more aggressive output feedback gains without compromising ammonia slippage effects. Proper choice of $\boldsymbol{K}_{\boldsymbol{s}}, \boldsymbol{K}_{\mathrm{NO}}$, and $\boldsymbol{K}_{\mathrm{NO}}$ is required in order to achieve the desired performance. In this work, a simple iterative algorithm was written that minimizes cumulative NOx emissions and constrains maximum $\mathrm{NH}_{3}$ slip to less than $1 \mathrm{ppm}$. Using the resulting gains $\left(\boldsymbol{K}_{\boldsymbol{s}}=[0.0650], \quad \boldsymbol{K}_{\mathrm{NO}}=15, \quad \boldsymbol{K}_{\mathrm{NO}} \boldsymbol{O}_{2}=15\right)$ with the grey-box model as a test plant produces the results shown in Fig. 14. Compared to the results in Fig. 11, it is evident that the designed controller results in higher SCR efficiency and significantly lower $\mathrm{NH}_{3}$ slip. Specifically, cumulative $\mathrm{NO}$ and $\mathrm{NO}_{2}$ emissions decreased by 8.1 and $11.4 \%$, respectively, while $\mathrm{NH}_{3}$ outlet decreased by $83 \%$. Maximum $\mathrm{NO}$ and $\mathrm{NO}_{2}$ emissions decreased from 366 to $344 \mathrm{ppm}$ and from 95 to $86 \mathrm{ppm}$, respectively. Finally, maximum ammonia slip which was the main performance requirement in this example decreased from 3.9 to less than 1 ppm ( $0.94 \mathrm{ppm})$.

It is noted that the methodology described above can be used for the design of other types of controllers based on linear control theory such as model predictive controller (MPC) and linear quadratic Gaussian (LQG). Finally, it is noted that choice of the number of piecewise linear models that will be generated is a tradeoff between desired accuracy and available 

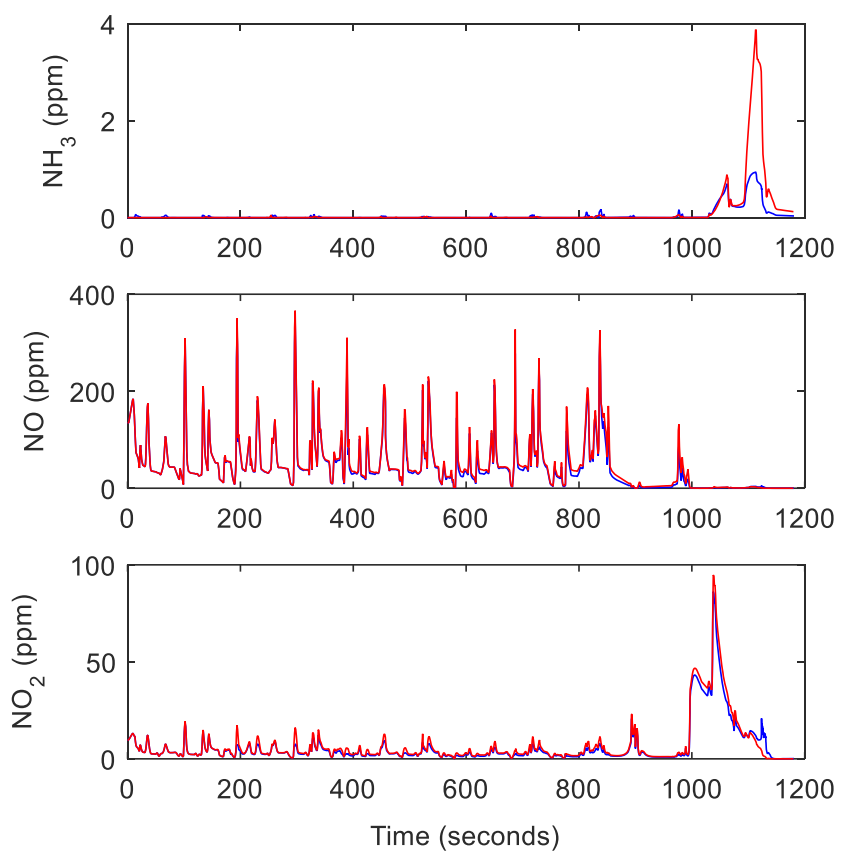

Fig. 14 Outlet species concentrations using observer-based state feedback controller in NEDC simulation

memory inside the ECU since the parameters for each one of the linear models must be stored in the ECU memory.

\section{Conclusions and Future Work}

In this work, a systematic procedure for developing a reducedorder model from a detailed model of monolith reactors is proposed. Using this procedure, we derived a reduced-order (grey-box) model for SCR reactor from a detailed $1+1 \mathrm{D}$ model. The resulting SCR grey-box model is essentially a zero-dimensional model and consists of reduced number of ordinary differential equations. Spatial gradients are taken into account by linking multiple zero-dimensional blocks. It was shown that the grey-box model predictions are accurate for a wide range of operating conditions, and it runs orders of magnitude faster than the $1+1 \mathrm{D}$ model. Grey-box model equations can be solved using an explicit ODE solver whereas $1+$ 1D model required an implicit ODE solver due to stiff nature of the equations. Finally, we linearized the model and developed an observer-based state-feedback controller and demonstrated the potential performance improvement when using model-based control design. Although mainly demonstrated in the context of SCR reactors, the procedure can be applied to other monolith reactors as well.

In this work, we did not account for the side reactions like $\mathrm{N}_{2} \mathrm{O}$ and $\mathrm{NH}_{4} \mathrm{NO}_{3}$ production, but these reactions can be easily included when necessary as these extra reactions do not pose any additional modeling difficulties. The pore diffusion effects are lumped into the kinetic parameters to simplify the model. There may be some applications where pore diffusional resistances are high, and hence, pore diffusion needs to be accounted explicitly. Internal mass transfer coefficient or an asymptotic solution approach can be used to explicitly account the pore diffusional limitations without increasing the computational burden. The SCR mechanism used in this work did not have inhibition terms in the rate expressions, but other applications like DOC and TWC contain inhibition terms in the rate expressions. Our future work will consider the pore diffusional limitations and reaction rate expressions with inhibition terms.

\section{References}

1. Johnson TV (2015) Review of vehicular emissions trends. SAE Int J Engines 8.2015-01-0993.

2. Skaf Z, Aliyev T, Shead L, Steffen T (2014) The state of the art in selective catalytic reduction control (No. 2014-01-1533). SAE Technical Paper

3. Yuan X, Liu H, Gao Y (2015) Diesel engine SCR control: current development and future challenges. Emission Control Science and Technology, 1-13

4. Chatterjee, D., Kočí, P., Schmeißer, V., Marek, M., Weibel, M., Krutzsch, B.: Modelling of a combined NOx storage and NH3SCR catalytic system for Diesel exhaust gas aftertreatment. Catal Today 151(3), 395-409 (2010)

5. Ericson C, Westerberg B, Odenbrand I (2008) A state-space simplified SCR catalyst model for real time applications (No. 2008-010616). SAE Technical Paper

6. Metkar, P.S., Harold, M.P., Balakotaiah, V.: Experimental and kinetic modeling study of NH3-SCR of NOx on Fe-ZSM-5, Cuchabazite and combined $\mathrm{Fe}$ - and $\mathrm{Cu}$-zeolite monolith catalysts. Chem Eng Sci 87, 51-66 (2013)

7. Zanardo G, Stadlbauer S, Waschl H, del Re L (2013) Grey box control oriented SCR model (No. 2013-24-0159). SAE Technical Paper

8. Song Q, Zhu G (2002) Model-based closed-loop control of urea SCR exhaust aftertreatment system for diesel engine (No. 2002-010287). SAE Technical Paper

9. Ong C, Annaswamy A, Kolmanovsky IV, Laing P, Reed D (2010) An adaptive proportional integral control of a urea selective catalytic reduction system based on system identification models (No. 2010-01-1174). SAE Technical Paper

10. Upadhyay, D., Van Nieuwstadt, M.: Model based analysis and control design of a urea-SCR deNOx aftertreatment system. J Dyn Syst Meas Control 128(3), 737-741 (2006)

11. Devarakonda M, Parker G, Johnson JH, Strots V, Santhanam S (2008) Adequacy of reduced order models for model based control in a urea-SCR aftertreatment system. SAE, 2008-01-0617

12. Hsieh, M., Wang, J.: Development and experimental studies of a control-oriented SCR model for a two-catalyst urea-SCR system. Control Eng Pract 19(4), 409-422 (2011)

13. Surenahalli HS (2013) Extended Kalman filter estimator for NH3 storage, NO, NO2, and NH3 estimation in a SCR (2013-01-1581). SAE Technical Paper

14. Groppi, G., Belloli, A., Tronconi, E., Forzatti, P.: A comparison of lumped and distributed models of monolithic catalytic combustors. Chem Eng Sci 50, 2705-2715 (1995)

15. Joshi, S.Y., Harold, M.P., Balakotaiah, V.: On the use of internal mass transfer coefficients in modeling of diffusion and reaction in catalytic monoliths. Chem Eng Sci 64(23), 49764991 (2009) 
16. Bissett, E.J.: An asymptotic solution for washcoat pore diffusion in catalytic monoliths. Emission Control Sci Technol 1(1), 3-16 (2015)

17. Gundlapally SR (2011) Effect of non-uniform activity and conductivity on the steady-state and transient performance of catalytic reactors. $\mathrm{PhD}$ thesis, University of Houston

18. Gundlapally, S.R., Balakotaiah, V.: Heat and mass transfer correlations and bifurcation analysis of catalytic monoliths with developing flows. Chem Eng Sci 66(9), 1879-1892 (2011)
19. Kamasamudram, K., Currier, N., Chen, X., Yezerets, A.: Overview of the practically important behaviors of zeolite-based urea-SCR catalysts, using compact experimental protocol. Catal Today 151, 212-222 (2010)

20. Brown J, Gu T, Artukovic D, Blint R (2015) Simulation of various SCR technologies applied to a $2.0 \mathrm{~L}$ diesel engine model to evaluate DeNox performance. CLEERS Workshop, Dearborn, USA

21. Gamma Technologies, GT-SUITE v7.5, After-treatment manual 